\title{
Is there a need to safeguard specialist psychiatric units in the NHS? Henderson Hospital: a case in point
}

\author{
Bridget Dolan, Research Fellow; and Kingsley Norton, Consultant Psychotherapist \\ and Honorary Senior Lecturer, Henderson Hospital, Sutton, Surrey SM2 5LT, and \\ Section of Forensic Psychiatry, St George's Hospital Medical School, London SW17
}

For the purpose of this article, a specialist psychiatric unit refers to any community project, out-patient clinic, hospital ward or, as in the case of Henderson, a whole hospital which specialises in providing a specific type of treatment or treatment to a particular patient group(s). Specialist psychiatric units may be particularly vulnerable at this time when, because of the implications of Working for Patients, many psychiatrists' minds are focused on the need to justify and define their 'core services'. Many specialist psychiatric units are directly funded by their hosting Region. If Regional Health Authorities do not maintain special psychiatric units directly then a high financial risk will be put on any District Health Authority or self-governing hospital which hosts them. If the latter fail to accept the financial risk, or take the risk and then suffer financially, there is the possibility that both a wealth of specialist expertise will be lost from the psychiatric profession as a whole and that certain patients will receive substandard or no treatment. It may be, therefore, that there is now a need specifically to justify the continued existence of specialist psychiatric units. Henderson Hospital, a therapeutic community specialising in the treatment of severely personality disordered young adults, is a case in point.

This paper summarises the history of Henderson Hospital over the past 40 years; outlines its clinical arena in terms of the specific (predominantly borderline) patient group; reports on key areas of research previously undertaken and points to future research directions. It also details some of the functions of a specialist unit; namely, training of qualified staff and students and providing advice to other agencies regarding management of difficult cases.

\section{Henderson Hospital}

In 1959 Henderson Hospital was so named when it became established as an autonomous unit. Before then, from 1947 when the Ministry of Labour set up the Industrial Rehabilitation Unit at Belmont, the clientele consisted of neurotic patients, often chronically disabled and unable to maintain a job, those with character disorders and those with borderline psychotic illnesses. The unit ran as a therapeutic community under the charismatic leadership of Maxwell Jones. In 1959, not only was the ideological separation from Belmont Hospital clearer, but the patients became "diagnostically differentiated as psychopaths or character disorders" (Whiteley, 1980).

The Industrial Rehabilitation Unit had been set up on an experimental basis by the then Ministry of Labour and through the years the research tradition has carried on. In 1954 a grant from the Nuffield Foundation enabled a large evaluative study to be conducted focusing upon the workings of the therapeutic community model (Rapoport, 1960). Testament to the importance of such research work is the existence on the permanent staff of a full-time research psychologist/sociologist post. Formal research from the Henderson has continued with the effect of producing greater definition of the patient population who most benefit from its treatment resources (Whiteley, 1970; O'Brien, 1976; Copas \& Whiteley, 1976), providing indications of what are the most beneficial aspects of the whole treatment programme (Whiteley \& Collis, 1987), suggesting which aspects of psychopathology are amenable to change and by way of which treatment ingredients (Norris, 1985), and identifying psychological and physiological characteristics of personality disordered patients (Gudjonsson \& Roberts, 1985). This auditing of itself by Henderson is in line with the Government's current argument for "the systematic, critical analysis of the quality of clinical care ... (to ensure) the best quality of service is being achieved within the resources available." (White PaperWorking Paper 6-Medical Audit).

Over the 30 years which have elapsed since Henderson's increasing specialisation in the treatment of 'psychopaths' and 'character disorders', there has been an enormous increase in interest in this field, particularly in the concept of 'borderline personality disorder' and 'borderline personality organisation'. This derives from two influences, one psychiatric and the other psychoanalytic.

\section{Personality disorder}

Henderson (1939) described the concurrence of psychiatric illness and abnormal personality and the very 
coexistence of such aspects justifies psychiatrists' continuing interest in personality disorder. There have been recent studies, some taking advantage of the DSM-III-R axis II definitions, which have explored the relationship of personality disorder: with suicide intent, with major depression in combination with dysthymic and cyclothymic disorders, in the families of depressed, schizophrenic and never ill probands, and in long-term non-psychotic patients.

The problem remains of providing a clinically valid description of personality disorder which can be reliably applied in clinical settings. The DMS-III$R$ axis II definitions have not yet fully resolved this problem, although research has been generated which may benefit from greater reliability if not validity. Because of continuing problems with terminology, accurate epidemiological data concerning the conditions have been hard to come by. In a community sample, $11.1 \%$ prevalence of (total) DSM-III personality disorders was reported (Reich et al, 1989). However, it is not known if increased interest in diagnostic entities contained under the umbrella term 'borderline' stems from an increasing prevalence of such disorders.

The recognition and successful management of abnormal personality and the personality disorder aspect of psychiatric patients and of their key social contacts represents an important element of psychiatric practice. The most worrying conclusion from the research just cited is the tendency for clinicians to adopt an attitude of therapeutic pessimism towards patients with a personality disorder and as a result the 'other' (Axis I) diagnosis is either inadequately assessed and/or inadequately managed.

\section{Borderline personality disorder (BPD) and borderline personality organisation}

BPD is one of the 13 personality disorders which appear in DSM-III-R. The DSM-III Task Force "had been faced with the sometimes idiosyncratic terminology used by individual clinicians, researchers, and theoreticians and with their varying ideas about exactly what this diagnosis included" (Kernberg, 1984). DSM-III opted for a more restricted definition rather than a broad spectrum one. Kernberg (1975) had adopted "an intermediary position which considers borderline personality organisation to be a psychostructural diagnostic entity ... indicating severity of character pathology or personality disorder" (Kernberg, 1984). Such a concept relating to severity, which has obvious clinical relevance, was not however introduced into DSM-III-R. The importance of severity of symptoms or behavioural abnormalities is a crucial one in the area of personality disorder, in order to differentiate it from abnormal personality and to allow quantification of pathology. The latter is important not only from an academic or theoretical viewpoint but also for those involved in providing services for personality disordered individuals (including those suffering from coexisting conditions). There is a range of psychotherapeutic approaches which may be more or less appropriate to different patients or to different phases of the disorder in a given patient. At one end of the range is supportive out-patient psychotherapy. It is those at the more severe end of the spectrum (i.e. with borderline personality organisation) who represent a large clinical challenge and who often necessitate institutional care of one sort or another. Some of these will be in the difficult and offender patient category and may be treated in medium secure units or special hospitals.

\section{Henderson Hospital residents}

From a descriptive or categorical diagnostic standpoint, residents at Henderson Hospital suffer from neurosis or personality disorder as defined by ICD-9 (or from neurotic, stress-related and somatoform disorders or disorders of adult personality and behaviour according to ICD-10). In terms of DSMIII-R Axis II diagnoses, residents come from the main three clusters of personality disorder type (but especially histrionic, narcissistic, anti-social and borderline - unified by their tendency to behave dramatically, erratically or emotionally).

This diagnostic diversity of the Henderson clientele, albeit within a particular band of the personality disorder diagnostic spectrum (if it can be conceived as such) may appear surprising. Edelson (1964) has argued for the importance of maximising homogeneity of diagnosis if there is to be an effective treatment outcome, particularly within a therapeutic community as at Henderson Hospital. What the Henderson residents have in common then is less the categorical diagnostic similarity and more the "genetic predispositions, psychodynamic predispositions and temperamental dispositions (which) converge" and which represent borderline personality organisation (Kernberg, 1984).

Some brief profiles of recent residents (whose identities have been protected through changing key details) may better serve to convey who are typical residents. There is no suggestion that the clinical presentations are race or gender-bound.

\section{Case 1}

Chris, a 24 year-old Caucasian male, was referred by a consultant psychiatrist following impulsive threatening behaviour, increasingly heavy alcohol intake and depression associated with a recent overdose in the context of a broken relationship. He also reported burning himself with matches when depressed and having bulimic symptoms, both binge eating and vomiting. 
His father had been murdered when he was aged 3 years. Subsequently, he went to live with his grandparents until aged 6 years, when his mother remarried. He returned to live with her, his stepfather and half brother in a mobile home. He described his mother as withdrawing all affection from him when his father died. At school he had few friends and was often in trouble for fighting and misbehaviour. $\mathrm{He}$ left with no qualifications. His delinquency began in early teens when he began using cannabis and abusing alcohol. While still a juvenile he was fined for breaking and entering and subsequently had nine other convictions including possession of drugs, threatening behaviour, drinking and driving. He had spent two years in custody. He had had six jobs since leaving school and was often sacked as a result of losing his temper. His current job had been held for one year. Socially he had few friends and his main social activity was playing football with 'street mates'. He had had one long-term relationship, living with a girlfriend who has a child by him.

At selection interview Chris was very suspicious and aggressive, but as the interview progressed he was able to show his vulnerable side and was close to tears at some points. His motivation to tackle his problems appeared good and it was felt that he could usefully work in groups and openly discuss his aggressiveness.

\section{Case 2}

Sara, a 21 year-old shop assistant, was referred by a consultant psychiatrist following repeated drug overdose and because of intractable obsessional symptoms over many years. She lived with her mother who was described as caring but quick tempered. She had never known her true father, who had left her mother when she was pregnant. When Sara was 3 years old, her mother had married and she had a half brother. As a young child she had been very dependent upon her mother and would follow her around from room to room, screaming if separated. She attended a child guidance clinic with her mother because of disturbed sleep and a lack of communication between them. She described continuous conflict with her stepfather from her early teens. He had sexually abused her between the age of 11 and 14 years. She did not make friends easily at school, but left with five CSEs and two $O$ levels at 16 . She attended a sixth form college but left after six weeks concerned that she could not complete her work perfectly. Since then she had six jobs, keeping one for over a year. She left most jobs because of worry that she could not perform well enough and felt inferior to her workmates. Socially she was very isolated and found it difficult to maintain conversations. Her two relationships were with much older men, one of whom became physically violent towards her.

She had been treated with psychotherapy techniques for six months before admission and had previously been admitted to psychiatric hospitals on three occasions. Cognitive behavioural therapy had provided little relief of symptoms. At selection she was extremely anxious but despite this, presented herself thoughtfully and openly to the group. She was able to acknowledge her need to come to terms with her sexual abuse. She was also keen to try to gain help for her obsessional symptoms.

Case 3

Lorraine, a 28 year-old medical secretary, was referred by a consultant psychiatrist (supported by her probation officer) diagnosed as suffering from 'explosive personality disorder' (301.3). She was an informal in-patient following an overdose. In hospital she had been verbally abusive to staff, broken windows and superficially cut her wrists.

Lorraine was an only child. She described her childhood, with both natural parents, as stable yet unhappy. She had never felt valued by her parents, whom she described as unemotional. Although family rows were infrequent there was an unusually tense atmosphere at home. She had never been able to control her temper or impulsive behaviour. She had left home at 18 and moved to London where she soon began taking drugs (LSD and IV heroin) and abused solvents and alcohol. She had withdrawn from the drugs with no specialist help and had been drug-free for two years at referral. She had taken approximately ten overdoses in the past and reported social phobia. Despite several offers of out-patient help she tended to default on treatment appointments. She had a lengthy forensic record, including theft, obtaining by deception, making hoax telephone calls and breach of the peace. She had twice broken a probation order and on referral was subject to a further probation order after conviction for GBH, attacking her partner's new girlfriend while intoxicated.

She presented as a highly tense and angry woman, tending to externalise her problems and minimising her destructive behaviour. However, it was felt that she was sincere in her wish to examine the roots of her problems and work on changing her behaviours.

Typically, Henderson residents have failed to engage in or maintain out-patient psychotherapy (whether supportive or interpretative). The reasons for this may vary from case to case and certainly some clinicians are unaware of the existence of borderline personality organisation or inexperienced in its detection and management. Without doubt, however, many of these patients are extremely difficult to engage in treatment, not least because of their failure to adopt the socially appropriate manner and behaviour of the 'patient'. They thus often give the appearance of being forced to attend an hospital appointment and to have no motivation of their own. Even after some initial engagement has been obtained, the patient may repeatedly withdraw into silence, answer off the point, or indicate that the interview is getting nowhere and that it would be better to terminate early (sometimes with the liberal use of invective). All these reactions require to be faced and clarified, and it is often necessary for the interviewer to take a particularly active stance and to confront the patient with an understanding of his/her ambivalence with respect to seeking treatment which, at bottom, is based on a belief that he/she is unworthy of help.

Henderson Hospital residents do not usually fulfil conventional selection criteria for psychotherapy. The severity of their acting-out and disruptive behaviour often means that they are not seen to be able to be contained in ordinary psychotherapeutic settings. However, they do need to have been able to display 
some evidence of personal maturity. Whiteley (1970), for instance, reports that (for men) a good outcome of treatment at Henderson is indicated by some "success in school, work or interpersonal relationships together with evidence of a capacity for emotional feeling and involvement in the living community affairs". A success in this context refers only to bare or relative success; for instance obtaining examination passes at school, occupational achievement in reaching at least a skilled manual job and maintaining work for a period of two years, and having maintained a relationship of an intimate kind but not necessarily sexual in nature. What is perhaps crucial is the phrase "capacity for emotional feeling" such as described in the case vignettes, since this shows a potential for basic interpersonal relating without which treatment in a therapeutic community, such as Henderson's, is impossible. This means that some patients with schizoid and some with sociopathic personalities, with whom it is impossible to achieve an empathic response or in whom it is impossible to observe emotions other than extreme fearfulness or rage, are unlikely to be helped by our therapeutic community approach.

\section{Role of Henderson Hospital within the NHS}

In common with many other specialist psychiatric units (especially those which like Henderson Hospital are not directly part of a larger teaching hospital) Henderson's primary role is the provision of a specialist treatment service, in this instance inpatient group psychotherapy in a therapeutic community context, to selected patients suffering from borderline personality organisation. For the most part Henderson is a secondary or tertiary referral centre, most referrals $(65 \%)$ are made by psychiatrists. Thus Henderson is currently perceived by those referrers as a specialist resource. The absence of sufficient similar facilities nationwide has produced, in effect, a supra-regional or national catchment area policy.

This specialist service is not only limited to those 60 people whom we admit annually. Although some referrals are not appropriate for admission, we assess over 100 per year and referrers receive advice on management and disposal of each case. (This aspect of a special unit's functioning is particularly important in rationalising, and limiting, the involvement of health care professionals with difficult and offender patients since this is a client group which draws in many professionals in an unwitting and disorganised manner to the detriment of the patient, exhaustion of the professionals and financial cost to the Health Service.)

Secondly, Henderson Hospital is a source of training to psychiatrists and other health care pro- fessionals. Many who have trained at Henderson have left it to found similar specialist units elsewhere. Training has also been provided to those working outside the UK, especially those from Scandinavia, who visited the Unit and took back to their native countries expertise obtained at Henderson. Both medical and non-medical 'trainees' have been involved. At present training is provided for a senior registrar in psychotherapy and a registrar as part of a general professional training scheme. Since 1976 there has been an annual course in group work for hospital staff, probation officers and residential social workers. This is a ten week day release course, offered at low cost, providing an experiential case of group analytic, therapeutic community and active group psychotherapy with supporting theory, including social dynamics of organisations. In addition, approximately 30 students spend placements from two weeks to six months in any given year. Mostly they are nursing students but they include also social work, probation, psychology and medical students. Also in each week an average of three visitors (health care professionals) spend a day in the community which is organised for them to obtain an experience of the inner workings of a therapeutic community.

Research is the third major role which Henderson has continued to play within the NHS in the 40 years since the original Industrial Rehabilitation Unit was established (for a resumé of such work see Whiteley, 1980). Since residents may stay for up to one year at Henderson, the emphasis is on studying in depth and there are many appropriate areas for research into borderline personality disorder. Not only is research into borderline personality disorder of importance for a greater understanding of the condition and its treatment, but it is required since the co-existence of personality disorder with other psychiatric (not to mention other medical) conditions is a factor which complicates and impairs treatment of the other (Axis I) conditions producing poorer outcome and higher cost, if not to the NHS itself then certainly to the nation. It has been demonstrated that borderline psychopathology is associated with high levels of psychiatric service use (in-patient, day care and emergency).

There is scope in these days of heightened interest in medical audit to cost the Henderson Hospital service in terms of comparison with non-Henderson treatment (often involving chronic or recurrent institutionalisation in psychiatric hospital or HM Prison). McGrath \& Lawson (1986) have noted the tendency for the assessment of psychotherapy in the NHS to concentrate exclusively upon clinical outcome. To the debate they have added the need for economic evaluation in terms of the reduction of demands upon other public services (social, medical and legal) against the cost of staffing and staff 
training. While fully concurring with their view, we would also stress the additional function of specialist units in that they play major roles in staff training; advising other agencies; development and improvement of treatment approaches; clearer definition of conditions and the forum for scientific research. Any service audit must consider each of these facets.

\section{Comment}

Henderson Hospital is not alone among specialist psychiatric units in facing an uncertain future. In the case of the Henderson Hospital, it is ironic that 1989, which brought the White Paper and the uncertainty about the future of such specialist units, also saw the 30th anniversary of its christening and the 50th anniversary of Professor D. K. Henderson's classic book Psychopathic States. However, it may be important while general psychiatrists are arguing the case for recognition of their services as 'core services' that the role of specialist psychiatric services is not overlooked. Many specialist resources whose treatment expertise, training input and advisory function, have taken years to develop and refine through research, risk being lost at a stroke of the bureaucratic pen.

\section{Acknowledgement}

We are grateful to the entire staff team at Henderson Hospital for their contribution towards the manuscript.

\section{References}

Copas, J. B. \& Whiteley, J. S. (1976) Predicting success in the treatment of psychopaths. British Journal of Psychiatry, 129, 388-392.
Edelson, M. (1964) Ego Psychology, Group Dynamics and the Therapeutic Community. New York: Grune \& Stratton.

GudJonsson, G. H. \& RoBerTs, J. C. (1985) Psychological and physiological characteristics of personality disordered patients. In Aggression and Dangerousness (D. Farrington \& J. Gunn). London: J. Wiley.

Henderson, D. K. (1939) Psychopathic States. London: Chapman \& Hall.

KERNBERG, O. (ed.) (1975) Borderline Conditions and Pathological Narcissism. New York: Jason Aronson.

- (1984) Severe Personality Disorders. New Haven: Yale University Press.

MCGrath, G. \& Lawson, K. (1986) Assessing the benefits of psychotherapy: the economic approach. British Journal of Psychiatry, 150, 65-71.

NoRRIS, M. (1983) Changes in patients during treatment at the Henderson Hospital Therapeutic Community during 1977-81. British Journal of Medical Psychology, 56, 2.

O'Brien, M. (1976) Psychopathic Disorder. PhD thesis. University of London.

RAPOPORT, R. (1960) The Community as Doctor. London: Tavistock.

Reich, J., Yates, W. \& Nduagoba, M. (1989) Prevalence of DSM-III personality disorders in the community. Social Psychiatry and Psychiatric Epidemiology, 24, 12-16.

WhITELEY, J. S. (1970) The response of psychopaths to a therapeutic community. British Journal of Psychiatry, 116, 517-529.

(1980) The Henderson Hospital. International Journal of Therapeutic Communities, 1, 38-58.

- \& Collis, M. (1987) The therapeutic factors in group psychotherapy applied to the therapeutic community. International Journal of Therapeutic Communities, 8, 21-31.

A full list of references is available on request to Dr Dolan.

\section{Correction}

\section{An inner city home treatment service for acute psychiatric patients. C. Dean and E. Gadd, Psychiatric Bulletin. December 1989, 13, 667-669}

At the end of the first paragraph under Findings on page 668 , it should read: There was no difference in the DSM-IIIR diagnoses between admissions and home treatment patients but there was a tendency for the home treatment group to have more patients with a psychotic diagnosis (Table I). 